\title{
Research of Cost and Benefit of Thermal Powers in Generation Rights Trade Under Energy-saving Power Generation Scheduling
}

\author{
Li ZHOU* \\ North China Electric Power University, No.2, Beinong Road, Huilongguan, \\ Changping District, Beijing, China, 102206 \\ e-mail: 18262308265@163.com
}

\begin{abstract}
The practice of Generation rights trade applied in Chinese electric power production tends to be mature, which exerts a great influence on energy-saving power generation scheduling in power plants. This article studies how thermal powers transfer their planned generation rights to wind power, solar power and hydropower to increase new-clean energy consumption in the power grid, as well as keeping their own economic benefit. Through analyzing energy consumption characteristics of thermal powers, I got coal consumption function of thermal powers. Then variable cost and pollution processing cost could be acquired. Plus fixed cost and opportunity cost, I got comprehensive cost of thermal powers under different output levels. Take one power plant in Shanghai for an example, I collected its generator's operating parameters and did research into its cost and benefit under simulation of power generation scheduling and generation rights trade. In conclusion, we should control generation rights the thermal power transferred to new-clean power within a certain range, in order to keep the power plant's economic profit. If exceeding the range, the thermal plant would conform risks of loss, even bankrupt.
\end{abstract}

Keywords-Energy-saving power; Generation scheduling; Generation rights trade; Thermal power cost composition; Cost and benefit analysis

\section{INTRODUCTION}

With the rapid development of wind power, solar power and other new-clean energy forms in China, some serious social problems have arose from increasingly difficult consumption of new-clean energy in power grid. Due to uncertainty of generation and inability of large-scale storage, new-clean energy is hard to be absorb in the local region.

It has proved to be practical that thermal power gives generation rights to new-clean power in or out of province. So, effective and reasonable generation rights replacement can contribute to energy conservation and emission reduction, as well as bringing extra profits for generation transferors and transferees.

So far, there have been many theses and reports studying about generation rights trade, most of them concentrated on trade feasibility, trade models and trade pricing mechanisms. Paper [1] constructs a model of generation rights trade among self-generation power plants, demonstrating that only by developing reasonable generation rights distribution systems can bilateral interests in generation transactions be guaranteed, and can a win-to-win situation be achieved. Paper [2] analyzes the generation rights replacement transaction model between new-clean energy power and thermal power based on the option theory. Through empirical calculation, it shows that option mode was better than the current opportunity cost mode of generation rights replacement transaction.

In regard to generation scheduling, many researchers have devoted themselves in this area. Paper [3] studies the optimal generation scheduling in thermal power plants, applying equal incremental method, dynamic programming method and rough set theory into generation energy-efficient scheduling optimization, giving comprehensive assessments to coal consumption of each generator, then determine the optimal power generation order. Based on energy consumption characteristics of hydro and thermal plants, in Paper [4], the technical condition under the installed capacity is introduced to build the energy consumption model for hydrothermal power systems and the comprehensive cost model, consequently seeking the best generation scheduling program for energy-saving goal.

When it comes to comprehensive generating cost of thermal power plants, Paper [5] does a detail analysis on the composition of plant cost, including fixed cost and variable cost. It fits the cost curve of generators under their different working conditions and finds that, total cost increases in the form of quadratic function with generation engine power and average cost has a decrease trend.

Whereas in China, there are yet no specific and integrate implementation standards and policies about generation rights transfer from thermal power to new-clean power. Considering that, in the generation rights transactions, thermal power plants are often at a disadvantage, so as to suppress their passion and initiative of continuously participating in power generation trade. In order to assist thermal plants in formulating a technically-feasible, economically-sound generation scheduling program, this article conducts a detailed cost-and-benefit analysis on thermal power generation rights transactions, certainly based on the former research results. Maybe I can make an effort to help China achieve the target of energy conservation and emission reduction, and pave the way for further reformation of electric market.

\section{THERMAL POWER GENERATING COST COMPOSITION AND CALCULATION METHODS}

In order to make scientific cost-and-benefit analysis, this section focuses on generating cost composition of thermal power generators and cost calculation methods.

The total cost of thermal power plants consists of the fixed cost and the variable cost by and large. The fixed cost is the power plant's expense that is not dependent on electric quantity generated by the plant. It does not 
change within a certain production scale. The variable cost is the expense that changes in proportion to electric quantity the plant generates.

While in the process of power generation, thermal power plants inevitably cause harmful and unrepairable damage to the natural environment. So the environmental cost should not be neglected. It includes resource consumption cost and pollution treatment cost. The environmental cost belongs neither to fixed cost nor variable cost. It increases with electric quantity generated, but not in a fixed proportion.

The opportunity cost, also known as alternative cost, is the value (not a benefit) of the choice of a best alternative cost while making a decision. In this article, it represents the thermal power plant's economic loss when it transfers generation rights to new-clean power.

The total cost can be expressed in a mathematic formula:

\section{$\mathrm{XTo} \tau \alpha \lambda=\mathrm{X} \Phi \imath \xi \varepsilon \delta+\mathrm{X} \varsigma \alpha \rho \imath+\mathrm{XE} \nu \varpi \imath+\mathrm{XO} \pi \pi \mathrm{o}$}

The specific steps of calculation are as followed:

\section{A. The Fixed Cost}

It includes material cost, wages and salaries, depreciation, repair expense and so on. The fixed cost is relevant steady and does not change as a function of power plants' activity. Material cost, wages and salaries; repair expense can be calculated according to the monthly cost sum of daily flows, which is then converted to average cost per hour.

When calculating depreciation, it needs to convert investments in each year to the first year in period of plant construction, and then add them up to get ' $I$ ':

$$
\begin{aligned}
& \quad I=I_{1}(1+i)^{n}+I_{2}(1+i)^{n-1}+\cdots+I_{n-1}(1+i)^{2}+ \\
& I_{n}(1+i) .
\end{aligned}
$$

where $I_{k}$ stands for investments in year $k$, ' $I$ ' is the total converted investments during the whole construction period (provided that annual investments take place at the beginning of each year), 'i' refers to the social discount rate plus the inflation rate. The construction period lasts for $\mathrm{n}$ years.

Then calculate the annuity A:

$$
\mathrm{A}=\mathrm{I} * \mathrm{i} *(1+\mathrm{i})^{\mathrm{t}} /\left[(1+\mathrm{i})^{\mathrm{t}}-1\right] .
$$

Where ' $t$ ' is the upper economic life limit of generators. Convert the annuity A into the daily cost, then divide it by 24 into average cost per hour.

\section{B. The Variable Cost}

The variable cost consists of fuel cost, water charge and expense of purchasing electricity. In this article, to simplify the calculation process, water charge and expense of purchasing electricity can be neglected for too small numeric value. Then the variable cost just equals to fuel cost (coal cost).

The coal consumption is determined by its' generator energy consumption characteristics and its operating efficiency (namely generation engine power).Generally, coal consumption changes with generation engine power in the form of quadratic function. The coal consumption F can be expressed by:

The coal consumption is determined by its' generator energy consumption characteristics and its operating efficiency (namely generation engine power).Generally, coal consumption changes with generation engine power in the form of quadratic function. The coal consumption F can be expressed by:

$$
\mathrm{F}(\mathrm{P})=\mathrm{aP}^{2}+\mathrm{bP}+\mathrm{c} .
$$

Where $a, b, c$ are the characteristic coefficients of generation engines, $\mathrm{P}$ is the power of generation engine. In a time interval $t$, electric generated by a generator is $\mathrm{E}$, which can be expressed in this way:

$$
\mathrm{E}=\mathrm{P} * \mathrm{t} .
$$

So the coal consumption per electric quantity is $\mathrm{f}$ :

$$
f=F t / E=a P+b+c / P .
$$

Then convert the coal consumption of a plant into standard coal consumption, when generation engine are operating under different working conditions, I compute the fuel cost per unit time, basing on the current coal price.

\section{The Environmental Cost}

The environmental cost includes resource consumption cost and pollution treatment cost. As to resource consumption cost, it is calculated with resource tax, including water consumption cost and coal consumption cost. While pollution treatment cost involves all the cost and expense of treating pollution like waste water, respirable particulate matters, poison air $\left(\mathrm{SO}_{2}, \mathrm{NO}_{\mathrm{x}}\right)$ and $\mathrm{CO}_{2}$ produced during electricity production. I get the average environmental cost after investigating and measuring generated energy, resource consumption, and pollution emissions.

\section{The Opportunity Cost}

When a thermal power plant transfers part of its generation rights to new-clean power plants, it would lose some economic benefits of selling the generation energy.

Consequently, add up $\mathrm{C}_{\text {Fixed }}, \mathrm{C}_{\text {Vari }}, \mathrm{C}_{\text {Envi }}$ and $\mathrm{C}_{\text {Oppo }}$ to get the comprehensive cost, which has a unit of yuan per hour. One point we have to notice is that the environmental cost, which is known to increase with the engine power, is difficult to measure and calculate. We can estimate the environmental cost by fixed ratio approach. The variable cost is a quadratic function of generation engine power, and the environmental cost is a linear function of generation engine power, so the total cost will be in form of a quadratic function of it:

$$
\mathrm{C}=\alpha * \mathrm{P}^{2}+\beta * \mathrm{P}+\delta \text {. }
$$

where $\delta$ is the idling cost (when generation engine works with no load). Then the average cost can be got:

$$
\overline{\mathrm{C}}=\alpha * \mathrm{P}+\beta+\delta / \mathrm{P}
$$


The marginal cost is acquired through the derivation of the total cost:

$$
\mathrm{MC}=\mathrm{C}^{\prime}=2 \alpha * \mathrm{P}+\beta .
$$

As we can see, the marginal cost increases with generation engine power in the linear function.

\section{COST-AND-BENEFIT ANALYSIS OF THERMAL POWER IN GENERATION RIGHTS TRADE}

Since the 1980s, China has been making efforts to build many thermal power plants, in order to meet the increasingly demand for rapid development of economy and electricity. Then, the market signed long-term supplying contrasts with thermal power plants to keep investment revenue of power plant construction. In the recent years, global environment degradation strongly calls for low carbon development. The world is going ahead to the energy-saving and pollution-reducing direction. New environmentally-friendly production and development strategy is shaking hands to us. However, long-term supplying contrasts with thermal plant have not be fulfilled. In this case, there exists a contradiction between new environmentally-friendly development strategy and the long-term supplying contrasts.

Generation rights trade is one of reasonable ways to solve the problem. By transferring generation rights among power plants, electricity industry can not only guarantee total supply, but also control pollution emissions produced by thermal power.

Generation rights trade between thermal power and new-clear power is helping to optimize electricity power supply structure, reduce non-renewable energy consumption and pollution emissions, through encouraging and promoting generation rights to transfer from high-cost, seriously-polluted power generators to low-cost and clean generators. This article does research into how thermal power plants transfer generation rights to wind power, solar power and hydropower, as well as making sure to keep their own economic benefit at the same time.

From the perspective of economy, generation rights replacement transaction is a trade based on equally sales. Generation transferors recover construction cost by selling generation rights, while transferees can save cost by producing electricity with effective generators and cutting down carbon emission. All in all, the two sides can achieve a win-to-win situation.

Cost-and-benefit analysis has a process as shown in Figure 1:

When generating hours of a power plant are fixed, its generated electricity can be adjusted by controlling generation engine power. If a generator is in the full capacity operation, then its output level is ' 1 '; If a generator works at half full capacity, it has an output level of $50 \%$.

When part of planned electric quantity in a thermal power plant is transferred to new-clean power plants, economic revenue will acquired by the thermal power plant from two direction: electricity sale on power grid and generation rights trade. Written in a mathematic formula, the total revenue is: Generated electric quantity $\times$ Pool purchase price-The total cost+Income from generation rights trade.

Regardless of price fluctuation of coal, and provided that all the electric generated by a thermal power plant can be sold, all the generation rights for transaction can be traded successfully as well. Pool purchase price is set as $P_{g}$, generation rights trade price is set as $P_{s} A$ thermal generator has a rated power of ' $A$ ', its output level is $\mathrm{x}$ at a certain time point. So, the total revenue of the thermal generator is:

$$
\rho(\xi)=(\mathrm{A}-\xi) * \Pi \gamma+\xi * \Pi \sigma .
$$

Which has a unit of yuan per hour. The total revenue changes with $\mathrm{x}$ ( $\mathrm{x}$ has a range from $40 \%$ to $100 \%$ ). In addition, the equation about $\mathrm{r}(\mathrm{x})$ can be used under two constraint conditions:

(1) The thermal power generation should work within its capacity scale:

(2) Total electricity supply should be kept constant before and after generation rights trade.

\section{A. Example Calculation}

In this section, I will do quantificational analyze about influences that generation rights trade has on a thermal plant's cost and benefit, thus assisting the thermal power plant in making scientific production decisions.

Take a thermal power generation with an installed capacity of 1,000 MW for an example, collect its operation parameters to calculate the total cost and total revenue under different output levels.

Cost calculation steps:

(1)The fixed cost: $\mathrm{C}_{\text {Fixed }}$.

(2)The variable cost: Coal consumption multiples coal price $\mathrm{P}_{\mathrm{Coal}}$. If the generator operates at the level $\mathrm{x}$, then coal consumption in an hour is:

$$
\Phi=\alpha * \Pi 2+\beta * \Pi+\chi=\alpha * \mathrm{~A} 2 * \xi 2+\beta * \mathrm{~A} * \xi+\chi .
$$

(3)The variable cost per hour is:

The environmental cost: Referring to international Carbon dioxide tax standard, I take the median of 10-50 yuan: 30 yuan; From Chinese Measurements of Pollution Emission Charge Standard, I get treatment costs of $\mathrm{SO}_{2}$, and $\mathrm{NO}_{\mathrm{x}}$. Besides, it's difficult to detect sort of solid particles in generation plants, so I take the mean value in 3 yuan per ton of coal on the average. Drawa standard for pollution treatment costs in the Table 1:

Having a combination with coal consumption, emission quantities of the five main pollution categories can be got. Multiple prices respectively and add up together, I can get the environmental cost: $\mathrm{k}^{*} \mathrm{x}$, $\mathrm{k}$ is the average environmental cost of the thermal power generator.

The comprehensive cost is:

$$
\underset{\varepsilon \delta}{\mathrm{X}}(\xi)=(\alpha * \mathrm{~A} 2 * \xi 2+\beta * \mathrm{~A} * \xi+\chi) * \Pi \mathrm{Xo} \alpha \lambda+\kappa * \xi+\mathrm{X} \Phi \mathbf{1} \xi
$$


Which has a unit of yuan per hour

If the power plant transfers $(1-\mathrm{x})$ proportion of its planned electric quantity, it will receive the total revenue:

$$
\mathrm{r}(\mathrm{x})=\mathrm{Ax} * \mathrm{P}_{\mathrm{g}}+\mathrm{A}(1-\mathrm{x}) * \mathrm{P}_{\mathrm{s}}
$$

The average revenue is

$$
\overline{\mathrm{r}}=\mathrm{A} *\left(\mathrm{P}_{\mathrm{g}}-\mathrm{P}_{\mathrm{s}}\right)+\mathrm{A} * \mathrm{P}_{\mathrm{s}} / \mathrm{x} .
$$

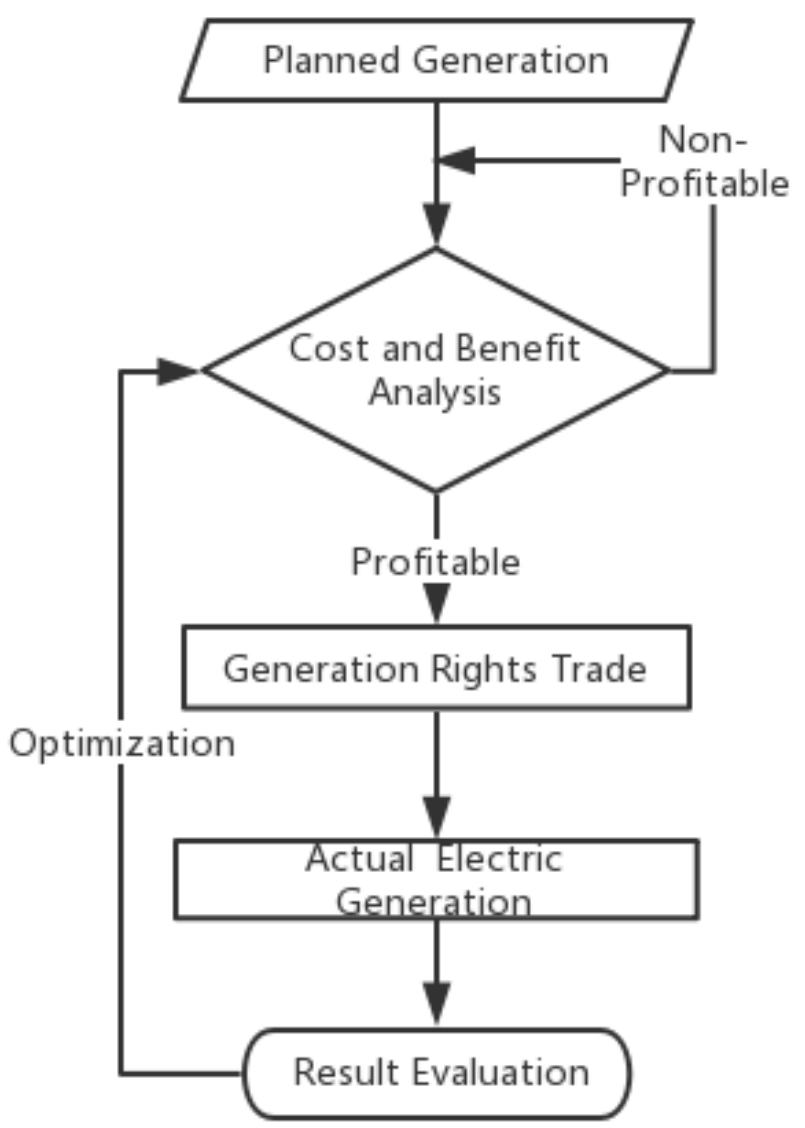

Figure 1. Cost-and-benefit analysis flow chart

TABLE I. POLLUTION TREATMENT COST STANDARD

\begin{tabular}{|c|c|}
\hline Category & Price \\
\hline Waste water & 0.27 yuan per cubic meter \\
\hline Carbon dioxide tax & 30 yuan per ton \\
\hline $\mathrm{SO}_{2}$ & 0.632 yuan per kilogram \\
\hline $\mathrm{NO}_{\mathrm{x}}$ & 0.632 yuan per kilogram \\
\hline Solid particles & 3yuan per ton of coal \\
\hline
\end{tabular}

Figure 2 tells moving trends of the average cost (AC) and the average revenue (AR):

The crossing point of AR and AC is the Shut Down Point of the thermal power generator. The point means that whether the plant transfers generation rights or not, the revenue the plant gets is the same. If the plant transfers generation rights, the total revenue can just compensate for the variable cost, not including the fixed cost. If the plant chooses not to transfer part of its generation rights, it will have not to pay the variable cost and cannot compensate for the fixed cost.

Curves of the total cost (TC) and total revenue (TR) are shown in Figure 3:

The crossing point of TC and TR is the Break Even Point of the thermal plant. If $\mathrm{x}$ at the Break Even Point is called $\mathrm{x} 0$, the output levels which exceed $\mathrm{x}_{0}$ can make the thermal power plant profitable, and vice versa.

\section{B. Analysis}

The thermal power generator with an installed capacity of $1,000 \mathrm{MW}$ is supposed to operate at output levels over 0.6, and transfers the rest generation rights to other plants. Only in this way can the plant totally compensate for the variable cost.

The thermal power generator with an installed capacity of $1,000 \mathrm{MW}$ is advised to work at output levels over 0.75 , and transfers the rest generation rights to other plants. Only in this way can the plant totally compensate for the comprehensive cost. The thermal power plant can be sure to benefit from the generation rights trade.

To conclude, output levels and generation rights for transaction should be controlled within the reasonable range calculated above paragraphs. If not, the thermal plant would conform the risk of loss. In addition, operating at the output level ' 1 ' can maximize the economic benefit for the plant. However, it is not helpful for the target of energy-saving and pollution-reducing development strategy.

When doing energy-saving generation scheduling decision-making, thermal power plants should do cost and benefit analysis referring to the specific steps in this section.

\section{CONCLUSIONS}

The article concentrates on studying the cost and benefit of thermal power plants after generation rights trade. In section 1 , I take the environmental cost into consideration, that is to say, impacts thermal plants have on environment is calculated. It is more comprehensive and sound.

Based on Chinese state policies on the electric market, research and study about generation rights trade in the article are just initial trail, and deficient in the breadth and depth, which needs further improvements. In the next step, I will do research into the economic effects of generation rights trade to the whole society and how to build a trade mode which makes positive effects maximized. Perhaps, linear programming and target programming will help me deepen the research continuously.

Proposals on advancing generation rights trade development in China:

(1) Strongly promote generation rights transferring from small fire generators to new-clean energy power, like wind power, solar power and hydropower.

(2) To broaden trade space, we have to solve problems involving generation rights transaction between different provinces. 
(3) To compensate for thermal power plants in disadvantaged situation, the Chinese government can give them appropriate subsidies, which can be negotiated by Thermal Power side and New-Clean Power side.

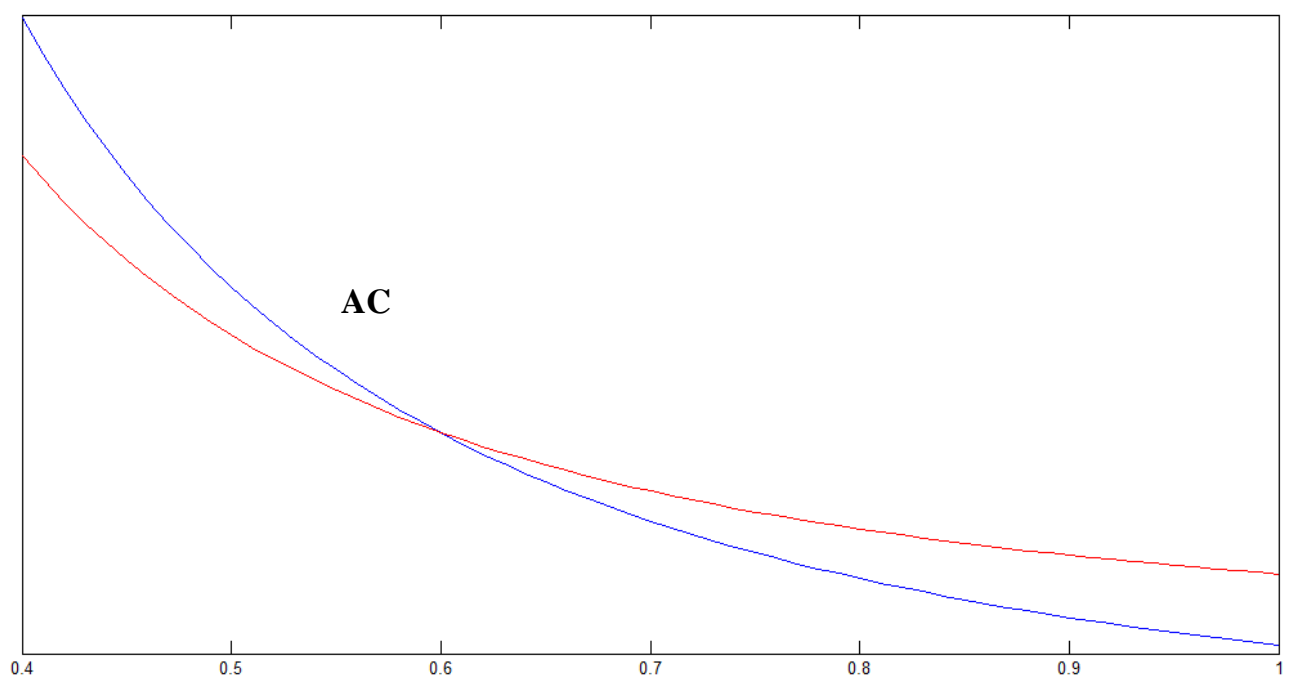

Figure 2. $\mathrm{AC}$ and $\mathrm{AR}$ curve

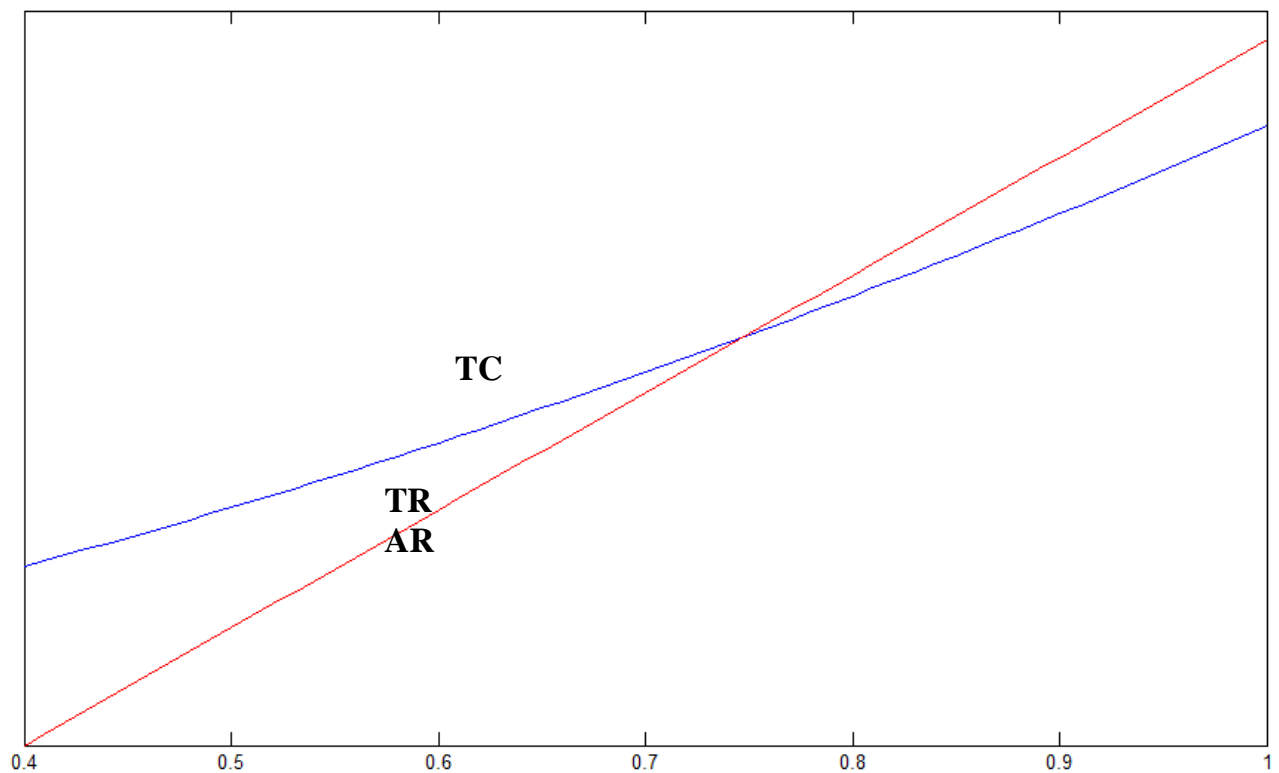

Figure 3. The total cost and total revenue per hour

\section{REFERENCES}

[1] HUA Xia, LUO Fan, ZHANG Jianhua, WANG Weiyuan LIU Fuchao, 2016, Automation of Electric Power Systems. (In Chinese)

[2] CHEN Tianen, LIU Ruifeng, YE Ze, DONG Xing, 2015, Journal of Electric Power Science and Technology. (In Chinese)

[3] ZHANG Jun, Optimization Research on Thermal Power Generation Dispatch Based on the Energy Conserving Dispatch
[D], North China Electrical Power University (Beijing), 2010.(In Chinese)

[4] LEI Shaolin, QIN Zhen, 2012, Modern Electric Power. (In Chinese)

[5] HUA Yangsong, Research on Real-time Generating Cost and Aided Price-bidding of power plant [D], North China Electrical Power University (Beijing), 2006. (In Chinese)

[6] ZHANG Xian, GENG Jian, PANG Bo, XUE Bike, LI Zhu, 2014, Automation of Electric Power Systems. (In Chinese) 